\title{
Electromigration studies in amorphous and polycrystalline alloys
}

\author{
M. F. Chishoim, D. B. Aaron, J. D. Whey, and J.H. Perepezko \\ University of Wisconsin-Madison, Department of Electrical and Computer Bngineening, Madison, \\ Misconsin $5 \$ 706$
}

(Received 28 March 1988; accepted for publication 10 May 1988)

\begin{abstract}
We report the first direct comparisons of electromigration in amorphous and polycrystalline thin-film samples of the same composition. Matched sample pairs of crystaline and amorphous $\mathrm{CH}-\mathrm{Ti}$ alloys were subjected to identical test conditions and tested to failure. It was found that the amorphous alloys tested show approximately one order of magnitude improved resistance to electromigration compared to their crystalline comterparts. The improved perfornance is attributed to the absence of grain boundary migration paths in the amorphous samples. These findings are consistent with earlier work that showed amorphous alloys to be effective diffusion barriers in thin-filln metallization systems.
\end{abstract}

Electromigration is an atomic mass-transport phenomenon in which atoms of a conductor are driven by the "electron wind," or Coulombic force, associated witr a large current density. ${ }^{i, 2}$ This phenomenon was studied intensively in the 1960's and 1970's when it was found to be one of the major failure mechanisms in the aluminum metallization Iines of integrated circuits. ${ }^{3-5}$ These eariy experiments showed that slectromigration proceeds most rapidy along grain boundaries, with depletion and accretion of the migrating atoms occurring primarily at grain boundary triple points. After sufficient migration has occurred, the depleted regions are macroscopically observable as voids that eventually destroy electrical contimity. Atoms that are removed from the void regions are typically driven to the surface where they form "hillocks." Voids and hillocks are the classic signatures of late-stage electromigration.

The realization that electromigration occurs aiong grain boundaries led Ames et al. ${ }^{7}$ to suggest that the electromigration resistance of aluminum metallizations could be increased by alloying the aluminum with copper which would then segregate at the grain boundaries, partially "blocking" them as migration paths. This strategy proved successful, and the use of $\mathrm{Al}-\mathrm{Cu}$ and $\mathrm{Al}$-Si alloys instead of pure $\mathrm{Al}$ has been standard in the $1 \mathrm{C}$ industry for many years. As linewidths have continued to shink, however, electromigration has again become a serious problem, even in these alloy netallizations. ${ }^{8.9}$ In previous work, we have shown that the absence of grain boundaries in amorphous alloys enabies these alloys to function as extraordinarly effective difusion barriers. ${ }^{10}$ This suggests that amorphous alloys may also show a high resistance to electromigration. In particular, amorvhous alloys lack both the easy migration paths (grain boundaries) and the nucleation sites that act as sources and sinks for migrating species (grain boundary triple points). Moreover, amorphous metals of en exhibit a negative temperature coeffcient for electrical resistivity which should serve to counteract the therma! runaway associated with electromigration failure. Thus it may be proposed that electromigration damage should be more difficult to initiate and sustain in anorphous materiais than in polyerystalline materials.

To test this proposal we deposited an amorphous Cu-Ti alloy on oxidized silicon substrates. The samples were depos- ited in a dc magnetron system, then removed and annealed in a furnace with an inert atmosphere. One-half of the samples were preannealed above their crystailization temperature, thereby causing them to become poiycrystalline. The rest were annealed below the crystallization temperature, but above the subsequent test temperature in order to decrease the possibility that relaxation effects would interfere with the electromigration results. "The samples were then patterned into test stripes for the electronigration experiments. Test stripes consisted of lines $5 \mu \mathrm{m}$ wide, $600 \mu \mathrm{m}$ long, and $500-700 \mathrm{~mm}$ thick, with $3 \times 3 \mathrm{~mm}^{2}$ bonding pads on each end.

The stripes of both sample types were subjected to identical test conditions (current density and actual sample temperature) in a test furnace while the voltage and current were monitored. The amorphous samples consistently showed better resistance to electromigration than their crystailine counterparts. In samples that were stressed with $2 \times 10^{6} \mathrm{~A} / \mathrm{cm}^{2}$ at line temperatures of $320^{\circ} \mathrm{C}$, the crystalline lines failed after only 25 to $40 \mathrm{~h}$, while the arnorphous lines lasted an average of $280 \mathrm{~h}$. Thus the amorphous lines showed approximately one order of magnitude improvement in the mean time to failure (Fig. 1). Actually, the observed failure times represent lower bounds for amorphous $\mathrm{Cu}$-Ti since the failure also involved a crystallization event. At this time, it is

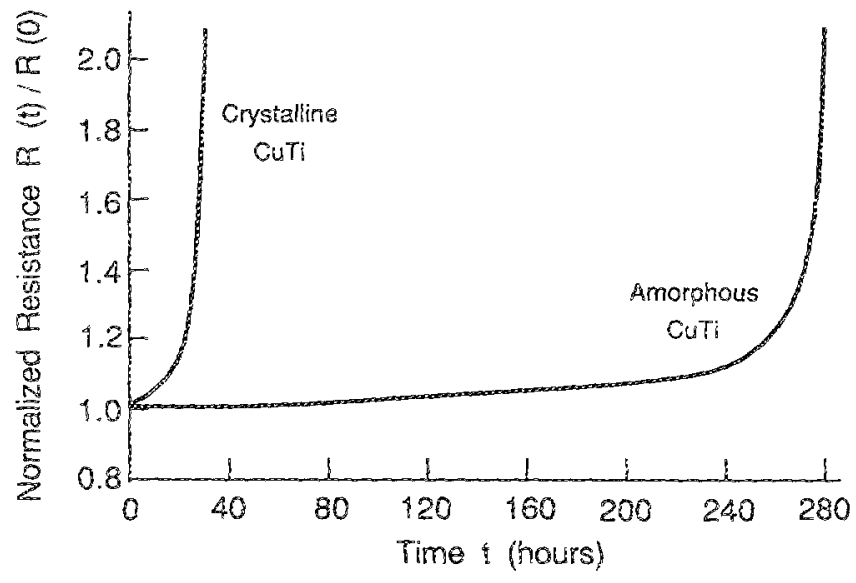

FilG. 1. Nommalized resistance us time plot of an anorphous Cu-Tiline, and acrystaline $\mathrm{Cu}$ - Ti line of the same composition and stressed under the same condicions: $320^{\circ} \mathrm{C}$ line temporature and $2 \times 10^{\circ} \mathrm{A} / \mathrm{cm}^{2}$ current density. 


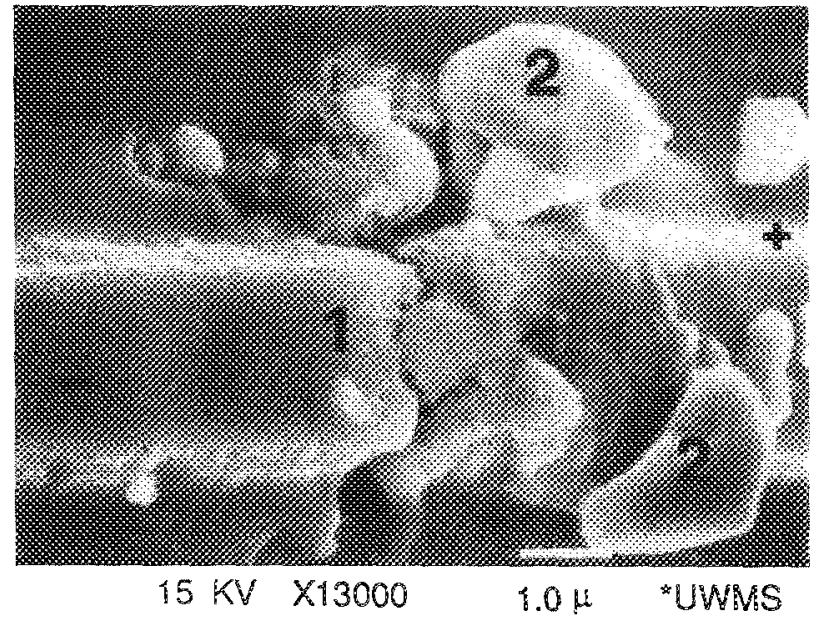

FIG. 2. SEM photograph of a failed crystainine Cu-Ti stripe. The composition of the line started as 55 at. \% Ti and 45 at. \% Cu. After clectromigration, region 1 was found to be over 80 at. \% Ti. The hillhocks (region 2) were composed alnust entirely of $\mathrm{Cu}$.

not clear whether crystallization preceded failure or was a consequence of the development of localized heating associated with incipient failure of the amorphous film. Similarly, in samples that were tested at less extreme conditions the amorphous lines showed less electrical restistance change because of electromigration than the crystalline lines.

The falled lines were examined using $x$-ray microanalysis to determine which species of the alloy migrated more readily than the other. It was found that in the crystaline Iine (Fig. 2) the copper was deffient atound the voids, particularly on the negative electrode side of the voids. The hillocks were found to consist almost entirely of copper. This indicates that the copper was the dominant migrating species.

Note, also, that multiple voids and hillocks were observed in the crystalline samples, indicating that migration damage was occurring in many parts of the sample simultaneous?y. In the amorphous samples we observed failure only at a single location (Fig. 3). After falure, examination showed high concentrations of titanum on the negative electrode side of the failed region; however, there were also higher concentrations of copper around the failue. The amorphous lines show no clear evidence of nillock formation, minor void, or whisker growth. In some of the failed amorphous samples, clear evidence of crystallization fronts perpendicular to the current direction was detected, leading us to believe that the lines localy crystallized during these experiments. Failures are most likely initiated in these crystalline regions.

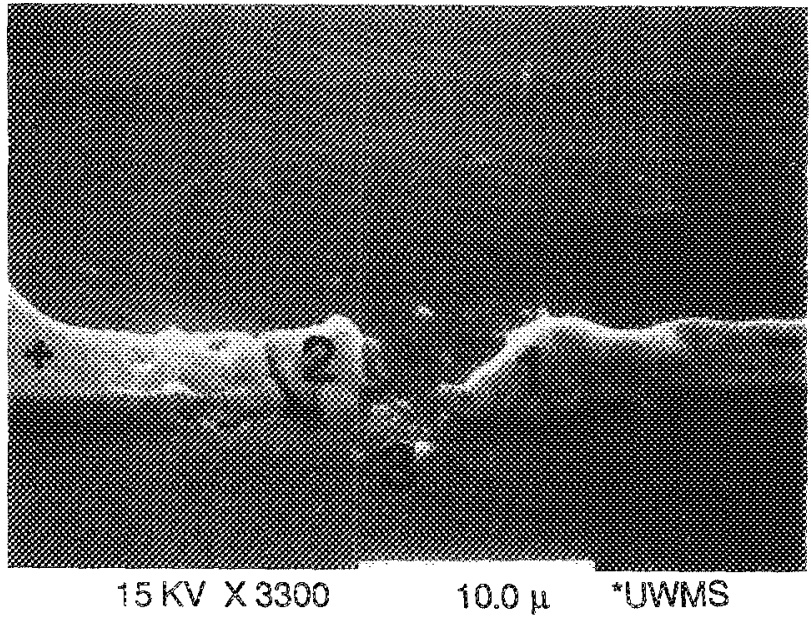

HG 3. SEM photograph of a irailed amorphous stripe of the same composition as the hine in $1 \mathrm{ig}$. 2. Again region 1 was found to be rich in $T i$. There was littl hillhock formation evilent in the amorphous samples; however, region 2 was found to be mostly $\mathrm{Cu}$. Notice the metal scatters in the thal phase of electromigration (region 3), presumably due to rapid melting in the final stages of line failure.

We have shown that amorphous alloys can ofer signifcantly improved electromigration resistance over thet crysalline counterparts. The order of magnitude improvement in average time to failure for amomphous metals provides another atribute for metallization application. Further investigation is underway 10 deternine both the sequence of events that accompany electromigration falure in amorphous metais and the activation energies in these alloys.

This work was supported in part by Department of Energy under contract No. DE-FG-85ER45096.

'Y. B. Fiks, Sov. Phys. Solid State 1, 14 (1959),

2H. B. Hentisgron snd A. R. Grone, B. Phys. Chem. Solds 20,76 (1961)

D. A. Rigney, in Charge Transfer/Electronic Siructure of Allops, edited by

I. H. Bennet and R. H. Willens (The Metallurgical Society of ABME, New York, 1974), pp. 87-\$25.

4. N. Pratt and R. G. R. Sellors, Difision and Defent Monograph Series ('Trans Tech, Riehen, Switzerland, 1973).

${ }^{5}$ F. M. D'Heurle and R. Rosenberg, Phys. Thin Films 7, 257 (1973).

R. L. Hummel, in Electro- and Themo-transport in Metals and Alloys, editcd by $\mathbb{R}$. E. Tummel and H. B. Huntington (American institute of Mining, Metallurgical and Perneum Fingineers, Inc. Pew York, 1977), pp. 93-107.

7. Ames, F. M. D'Leurie, and R. E. Hotstmann, IBM J. Kas. Dev. 14,80 (1971).

"Y. Paulean, Solid State Technol. 34, 101 ( 1987 ).

H. H. Hoang and J. M. MeDavid, Sold State Technol. 39, 121 (1987).

"R. E. Thomas, K. J.Guo, D. B. Aaron, E. A. Dobisz, J. H. Perepezko, and J. D. Wiley, Thin Solid Films 150, 245 (1987).

'E. A. Dobisz. B. L. Doyke, $J$. H. Perepezko, J. D. Wiley, and P. S. Peerey, Mater. Res. Soc. Syrmp. Proc. 37,479 (1985). 